\title{
Research on the Mode of Cultivating Practical Talents of Cross-border E-commerce in Higher Vocational Education based on Market Demand
}

\author{
Xianglei Meng \\ Jilin Technology College of Electronic Information, Jilin, Jilin, 132021
}

Keywords: Practical Talents, Cross-border E-commerce, Higher Vocational University

\begin{abstract}
With the advancement of the process of economic globalization, China's business and work are gradually being promoted, of which, cross-border e-commerce personnel training is the most important work. Vocational colleges as a social transport professionals based on the birthplace of cross-border e-commerce personnel training work plays a very important role. From the perspective of the development of e-commerce, society and enterprises have a very urgent need for cross-border e-commerce professionals. In this context, vocational colleges should seek to cultivate cross-border e-commerce talents of the new path for the social transport of talent. This paper starts from the current situation of cross-border e-commerce talents training in China, analyzes the professional ability requirements of cross-border e-commerce specialty, and enumerates the obstacles encountered in the current training of cross-border e-commerce talents in vocational colleges. Based on the mode of integration of production and education of vocational colleges in cross-border e-commerce personnel training made a number of recommendations.
\end{abstract}

\section{Introduction}

Higher vocational education is a high - quality skilled talents. Qualified vocational graduates are working in the first line, understand the technology, will operate, can manage, have a certain professional quality of the technician. Therefore, vocational teaching should be based on vocational skills training to focus on the application of technical operations to develop students' independent operational capacity to "application" as the main purpose to market demand-oriented, curriculum and adjust the teaching content. Skills is the accumulation of experience, suitable for real work in the access to professional quality also need to develop in a certain professional environment. "School-enterprise cooperation, production and education integration," the training model and the concept of higher vocational education: vocational education and industry depth cooperation, the combination of schools and enterprises, teachers and students with front-line staff, theory and practice.

With the rapid development of foreign trade online transactions characterized by small single frequency, the gap between the cross-border e-commerce talents who can carry out transnational commerce and trade activities through Internet means is getting bigger and bigger. Excellent cross-border e-commerce talent, should have a good professional quality, understanding of international trade, international payment, international logistics and cross-cultural exchanges and other professional knowledge, proficient in English shop management, online communication in English, to overseas Market research, network store optimization and product promotion. The use of production and education integration model, school and business docking, curriculum content and professional standards docking, teaching process and production process docking, cultivate cross-border e-commerce business ability, knowledgeable, skilled in some cross-border third party Platform operation, in line with market and cross-border e-commerce job needs. 


\section{Opportunities in the Process of Cultivating Talents in Higher Vocational Colleges}

Cross-border electricity business subordinate to e-commerce or international trade in a class of training in the direction, only this point, is sufficient to show that cross-border e-commerce in the training foundation is not strong enough. As cross-border electric business does not belong to the professional directory, and thus colleges and universities in the development of curriculum and set the course content is difficult to grasp the focus. On the current curriculum, cross-border e-commerce is only in the surface form. This mode of teaching or training mode just reflects the talent training program, goals and positioning is very vague. The reason for this situation is that the development of cross-border electricity business is still relatively short time, the domestic understanding of this understanding there are some limitations. In addition, vocational colleges in the training of personnel in this area, only think of how to meet the market supply and demand, for the long-term development of regional economy did not do a comprehensive analysis, so that the professional and curriculum is difficult to achieve the desired objectives and teaching results. In view of the professional construction of cross-border electric business, it is necessary to arrange different courses depending on the characteristics of the specialty. However, in fact, most institutions do not consider this point. If the cross-border electrical business professionals set in the international trade directory, the course content should be biased emphasis on management; if the cross-border electrical business professionals set up under the e-commerce, the course content should be biased towards technology.

Cross-border e-commerce, for the various institutions, are relatively unfamiliar. Cross-border electricity business in a short period of time to develop, and thus in the academic and application areas are in the initial stage. On the current situation, with a fully meet the needs of cross-border e-commerce teaching staff, but also some time. Although the vocational colleges opened a cross-border e-commerce professional, but the teaching of teachers generally lack. The school will only teach e-commerce, international trade, marketing, business English, web design and other professional content of the teacher to carry out teaching activities. The teachers who have switched from their profession are not solid, and the knowledge of cross-border electricity is not profound, so that the course of teaching is not practical. In addition, these teachers do not have the actual combat experience, but can not be useful to impart knowledge to students.

In the process of cross-border electricity business, teachers need to contact the actual, to give students a demonstration. Therefore, after the appropriate theoretical teaching, to more practice teaching. However, by the lack of infrastructure or other factors, the practice of teaching in colleges and universities is not smooth. As we all know, practical teaching is inseparable from the training room and off-campus practice base. Teaching software simulation of cross-border electricity business environment is an indispensable part of the practice of teaching, but if the school conditions are limited, this demand simply can not meet. In short, engaged in cross-border electricity business work, the need for students to practice the ability to cross the border. At present, most institutions are in practice ability, but off this level.

\section{Suggestions on Cultivating E - commerce Talents in Higher Vocational Colleges}

The construction of curriculum system is the key to ensure the quality of teaching. To build a scientific and reasonable curriculum system, we should set up the course group and the core of the core skills. In order to cultivate qualified cross-border e-commerce talents, the school requires students to complete the basic culture courses, related professional courses, professional training courses and cross-border e-commerce platform to implement the contents of the four modules. Basic culture course "necessary, enough" for the degree, the relevant professional courses according to the cross-border e-commerce job post group targeted to set up specialized teaching modules, professional training courses and cross-border e-commerce platform practice focus on specialized skills and professionalism , The ability to innovate and develop. In addition, because the majority of cross-border e-commerce platform for the use of language is English, so many companies pay 
special attention to students' English listening and speaking ability, then cross-border e-commerce personnel training system must highlight the use of English ability, each semester Should be related to the provision of relevant English courses, especially listening and speaking courses.

The introduction of cross-border e-commerce enterprises. To the existing school students and teachers resources and training room equipment (venues, computers and networks) as the carrier, the introduction of foreign trade enterprises to join, cross-border e-commerce platform operation and personnel training. Combined with the teaching needs, so that students gradually participate in batches, regular rotation, in practice to learn. Schools to arrange the relevant teachers to attend classes to participate in practical exercises and guidance, counseling students to learn and practice; enterprises to arrange experienced front-line staff as part-time teaching staff, according to the combination of teaching and learning to complete part of the teaching work.

Introduce platform training courses. Dunhuang network, speed selling and other major cross-border e-commerce platform In order to expand the business, are for their own platform characteristics and practical skills, cultivate a large number of professional lecturers, but also planning a series of courses, these courses can be introduced vocational courses Teaching, so as to help students after graduation to become "zero adaptation period" of cross-border e-commerce business new employees.

The introduction of excellent training institutions. Training institutions have a large number of cross-border e-commerce combat experience with a large number of lecturers and mature training course system, in the short term to help students in a number of cross-border platform to successfully shop, and even successfully deal with foreign buyers, so that students learn something Into, learn to use.

Cross-border e-commerce is a very practical course, entrepreneurial practice can enhance the interest and enthusiasm of students to learn the course, to stimulate students to engage in foreign trade positions enthusiasm. Cross-border electricity business retail industry threshold is relatively low, part of the platform free and can be zero inventory, to bring opportunities for students to start. It is necessary for the school to organize professional teachers and business experts to set up a professional team to guide and assist outstanding students to start a business. First of all, the professional team should create a business atmosphere, inviting businessmen to entrepreneurs to school entrepreneurship guidance and exchange, to stimulate students enthusiasm for entrepreneurship. You can organize electric business venture contest, guide students to start and through the game to accumulate entrepreneurial experience. Second, the professional team should be based on the full investigation, the use of student entrepreneurship of the various support policies, select some suitable projects to guide students to participate in entrepreneurship. Again, the professional team can set up a venture fund to solve some of the problem of student turnover. Finally, the professional team can also help students contact the factory to ensure supply.

It is not comprehensive to train high-level cross-border e-commerce talents, and it is not comprehensive to use the test scores to assess the learning effect, especially for the students who set up their own shops and participate in entrepreneurship. If the students can through professional learning and after school practice, to achieve a certain amount of sales or to achieve a certain profit and successful business, assessment model of diversification is even more important. Cross-border e-commerce personnel training, theoretical test scores of course can not be completely ignored, but the actual results of the assessment is also very important. For most students, the number of products released in the practice, product quality, sales performance, profits and so can be used as the basis for assessment, combined with student performance, final results, practical summary and other comprehensive assessment of student achievement, so that more comprehensive To test the student's learning and practical ability. For the choice of entrepreneurship students, students of entrepreneurial performance assessment can be used as part of the student performance assessment can even replace part of the theoretical class results, so as to ensure the conduct of entrepreneurial practice.

Vocational colleges and universities to cultivate cross-border e-commerce talent, mainly engaged in foreign trade e-commerce, cross-border e-commerce, network marketing, electronic customs, 
freight forwarding, import and export trade, with the single work. In short, colleges and universities need to train high-end skilled professionals for these areas of application. After confirming this goal, the school should set up the course accordingly. To set the job skills requirements set the main course, but should focus on the core skills. On the set of courses, should be broadly divided into four modules, namely the basic culture courses, related professional courses, professional training courses and cross-border e-commerce platform practice classes. Basic culture class to lay a solid foundation, related professional courses involved in cross-border e-commerce professional job requirements, professional training courses to develop professional skills, cross-border e-commerce platform to practice vocational skills. Cross-border e-commerce platform for the exchange of foreign language applications, therefore, for the ability to learn English can not be sloppy.

\section{Conclusion}

The traditional e-commerce talent can only be qualified for the traditional e-commerce positions, and cross-border e-commerce talent in the job capacity and competency conditions have a new requirement. This is not only to meet the needs of economic globalization, but also to meet the needs of cross-border e-commerce development. In this situation, vocational colleges should shoulder their own responsibility, to develop a professional level of e-commerce solid, cross-cultural communication ability of talent. Colleges and universities in the process of cross-border e-commerce personnel training, should be cross-border e-commerce personnel training objectives and requirements as a benchmark, from a reasonable curriculum system to create a comprehensive cross-border e-commerce innovation and entrepreneurship education practice platform, the application of appropriate assessment methods and The establishment of professional quality of the high level of cross-border e-commerce teachers to improve the quality of cross-border e-commerce education in colleges and universities to enhance the professional quality of cross-border e-commerce professionals, and thus promote the steady development of cross-border e-commerce industry.

\section{Acknowledgements}

The 13th Five - Year Plan of Educational Science in Jilin Province

Project Name: Research on the Mode of Cultivating Practical Talents of Cross-border E-commerce in Higher Vocational Education Based on Market Demand

Number: GH16536

\section{References}

[1] Chen Dan. On the market-oriented e-commerce personnel training model [J]. Science and Technology Economic Guide. 2017 (22)

[2] Wang Qi. "Internet +" era of higher vocational education of e-commerce personnel thinking [J]. Finance theory and teaching. 2017 (04)

[3] Jin Jiedong. Higher vocational e-commerce personnel training in the existing problems [J]. Curriculum Education Research. 2014 (34)

[4] Liu Xingmin, Chu Jinhua. Higher vocational e-commerce talent training model and positioning thinking [J]. Liaoning Higher Vocational Journal. 2012 (05)

[5] He Shangfei. On the cultivation of e-commerce talents [J]. Vocational Education and Economic Research. 2005 (02)

[6] Sun Huiru. Vocational colleges of cross-border e-commerce talent core competence training [J]. Shopping modernization. 2017 (06) 